\section{Severe respiratory depression after epidural morphine in a patient with myotonic dystrophy}

Kohji Ogawa MD, Hiroshi Iranami MD, Takeshi Yoshiyama MD, Hiroshi Maeda MD, Yoshio Hatano MD
We describe a patient with myotonic dystrophy who underwent cholecystectomy, and developed severe respiratory depression following epidural administration of morphine to provide postoperative analgesia. At preoperative assessment, he demonstrated near normal vital capacity and maximal voluntary ventilation, but the presence of chronic ventilatory failure with a resting value of $\mathrm{PaCO}_{2} 51 \mathrm{mmHg}$. Anaesthesia was produced by a combination of epidural and light general anaesthesia without intravenous anaesthetics, narcotics or neuromuscular relaxants. Five hours after epidural administration of $2 \mathrm{mg}$ morphine, the patient developed severe respiratory depression with a $\mathrm{PaCO}_{2}$ of $93 \mathrm{mmHg}$. Intravenous naloxone resulted in transient improvement in minute volume, suggesting that epidural morphine was responsible for the depression. Epidural morphine can cause unexpected respiratory depression, even at a small dose, because of the sensitivity of the respiratory centre to morphine in patients with myotonic dystrophy.

Un patient atteint de dystrophie myotonique est opéré pour une cholécystectomie. Il développe par la suite une dépression respiratoire grave après l'administration épidurale de morphine pour l'analgésie postopératoire. Au moment de l'évaluation préopératoire, ses tests de fonction pulmonaire révèlent une capacité vitale presque normale et une ventilation volontaire maximale, mais aussi des signes d'insuffisance respiratoire chronique dont une $\mathrm{PaCO}_{2}$ à $51 \mathrm{mmHg}$. L'anesthésie consiste en une association épidurale avec anesthésie générale légère sans in-

\section{Key words}

ANALGESIA: epidural;

ANALGESICS: morphine;

COMPLICATIONS: respiratory; MUSCULOSKELETAL: myotonic dystrophy.

From the Department of Anesthesiology, Wakayama Medical College, Wakayama, Japan.

Address correspondence to: Dr. Yoshio Hatano, Department of Anesthesiology, Wakayama Medical College, 7-Ban-cho 27, Wakayama, 640, Japan.

Accepted for publication 30th June, 1993. jection iv d'anesthésiques, d'opiacés ou de myorelaxants. Cinq heures après l'administration épidurale de morphine $2 \mathrm{mg}$, le patient entre en dépression respiratoire profonde avec une $\mathrm{PaCO}_{2}$ qui monte à $93 \mathrm{~mm} \mathrm{Hg}$. De la naloxone intraveineuse produit une amélioration transitoire du volume-minute, ce qui suggère que la morphine épidurale est responsable de la dépres sion. La morphine épidurale peut provoquer une dépression respiratoire inattendue, même à petites doses à cause de la sensibilité à la morphine du centre respiratoire des malades atteints de dystrophie myotonique.

Myotonic dystrophy is an uncommon inherited disease which is characterized by muscle atrophy, muscle rigidity and endocrine disorders. ${ }^{1-3}$ There is a high incidence of complications such as respiratory failure or arrythmia in the perioperative management of patients with myotonic dystrophy. ${ }^{1-4}$ Respiratory failure, in particular, is one of the most common causes of postoperative morbidity. ${ }^{5}$ Not only wasted respiratory muscles but also abnormal sensitivity to opioids and some anaesthetics are considered to lead to perioperative respiratory impairment. ${ }^{1-6} \mathrm{Al}-$ though it is generally accepted that systemic administration of these drugs may cause severe and prolonged respiratory depression, ${ }^{1-6}$ there have been no reports of severe respiratory depression caused by epidurally administered opioids in patients with myotonic dystrophy. This case report describes severe respiratory depression caused by a small dose of morphine hydrochloride administered into the epidural space in a patient with myotonic dystrophy.

\section{Case report}

A 50-yr-old man weighing $60 \mathrm{~kg}$ was scheduled for cholecystectomy. He had developed myotonic dystrophy at the age of $40 \mathrm{yr}$, and on admission he showed the characteristic features of patients with this disease, such as frontal baldness, ptosis, hatchet face due to facial and temporal muscular atrophy, wasted sternocleidomastoid and masseter muscles, and distal muscle atrophy of the upper 
and lower limbs. He also exhibited mild dysarthria and grip myotonia. On physical examination, blood pressure was $110 / 60 \mathrm{mmHg}$ and heart rate $68 \mathrm{~min}^{-1}$. Pulmonary function testing revealed near normal vital capacity and maximal voluntary ventilation $(82.5 \%$ and $91.3 \%$ of the predicted normal values, respectively). Arterial blood gas analysis revealed moderate hypoxaemia and hypercapnia, with pH 7.32, $\mathrm{PaO}_{2} 70 \mathrm{mmHg}$, and $\mathrm{PaCO}_{2} 51 \mathrm{mmHg}$, but a chest $x$-ray showed no abnormalities. Although electrocardiography revealed incomplete right bundle branch block with sporadic premature ventricular contraction, ultrasonic echocardiography showed no organic involvement of the heart. Endocrine disorders commonly seen in this disease were not obvious. Results of haematological and biochemical studies were all within normal limits.

Premedication consisted of lorazepam $0.5 \mathrm{mg}$ po and atropine sulphate $0.5 \mathrm{mg} s c$ one hour before induction of anaesthesia. Following placement of an intravenous catheter in the arm, an epidural catheter was inserted via the $T_{8-9}$ interspace. Exact placement of the catheter in the epidural space was confirmed by absence of an increase in heart rate after administration of $2 \mathrm{ml}$, lidocaine $2 \%$ solution containing epinephrine via the catheter as a test dose. Anaesthesia was induced with nitrous oxide and halothane in oxygen. Fifteen minutes later, the trachea was intubated without the use of neuromuscular relaxants. Anaesthesia was maintained with epidural anaesthesia, and nitrous oxide $50 \%$ and isoflurane at an end-tidal concentration of $0.2 \sim 0.5 \%$ in oxygen. Ten minutes before initiation of surgery, $7 \mathrm{ml}$ mepivacaine $2 \%$ were given epidurally followed by $5 \mathrm{ml}$ given twice every $50 \mathrm{~min}$ during surgery. Hypotension induced by epidural anaesthesia was corrected by intravenous volume loading and dopamine hydrochloride $i v$ at a rate of 3 $\mu \mathrm{g} \cdot \mathrm{kg}^{-1} \cdot \min ^{-1}$. Surgery was completed uneventfully within $80 \mathrm{~min}$ without the use of neuromuscular relaxants. After termination of nitrous oxide and isoflurane, the patient promptly regained consciousness and was able to maintain adequate ventilatory volume with a minute volume of $5.8 \mathrm{~L}$. Arterial blood gas analysis demonstrated the $\mathrm{PaCO}_{2}$ of $48 \mathrm{mmHg}$ and $\mathrm{PaO}_{2}$ of $340 \mathrm{mmHg}$ during spontaneous ventilation breathing $100 \%$ oxygen. The trachea was then extubated and he was transferred to the intensive care unit for further observation.

Oxygen was administered via a clear face mask at 5 $\mathrm{L} \cdot \mathrm{min}^{-1}$ and the patient's respiratory status remained stable in the intensive care unit. Although $5 \mathrm{ml}$ bupivacaine $0.125 \%$ was administered epidurally twice for postoperative analgesia during the seven hours after surgery, its analgesic effect lasted for only two hours. Morphine hydrochloride $2 \mathrm{mg}$ and $5 \mathrm{ml}$ bupivacaine $0.125 \%$ were then injected epidurally nine hours after surgery. No opioids had been administered by any route during anaesthesia and up to this point postoperatively. Two hours later, the patient's respiratory rate was $12 \cdot \mathrm{min}^{-1}$ and $\mathrm{PaCO}_{2}$ appeared to slightly increase to $54 \mathrm{mmHg}$, while the level of consciousness was clear. Five hours after epidural morphine, he developed severe respiratory depression, with a respiratory rate of $10 \mathrm{~min}^{-1}$ and $\mathrm{PaCO}_{2}$ of $93 \mathrm{mmHg}$, necessitating tracheal intubation and mechanical ventilation. At that time he was noted to be somnolent. Intravenous administration of naloxone $0.2 \mathrm{mg}$ produced a transient improvement in consciousness and increase in the respiratory rate from 10 $\mathrm{min}^{-1}$ to $15 \mathrm{~min}^{-1}$ and in the minute ventilatory volume from 3.8 to $5.5 \mathrm{~L}$. However, ventilatory support was continued for a further $20 \mathrm{hr}$, after which the trachea was extubated and the patient was returned to the general surgical ward. The rest of the postoperative course was uneventful, and he was discharged 18 days after the operation.

\section{Discussion}

The perioperative management of patients with myotonic dystrophy presents many problems such as arrythmia, muscle rigidity and impaired respiratory function. ${ }^{1-4}$ In particular, postoperative respiratory failure is a common cause of postoperative morbidity. ${ }^{5}$ Respiratory dysfunction is caused not only by impaired ventilation due to wasting of the diaphragm and respiratory muscles, but also by susceptibility of the respiratory centre to anaesthetics and opioids. ${ }^{1-6}$

In this patient, severe respiratory dysfunction was manifested by a high $\mathrm{PaCO}_{2}$ and the slight reduction of respiratory rate $14 \mathrm{hr}$ after surgery (five hours after epidural administration of morphine). Intravenous administration of naloxone reversed this respiratory depression, strongly suggesting that the epidural morphine was responsible for the depression. Hypoventilation due to the inherent muscle weakness was ruled out because anaesthesia and surgery were completed without administration of neuromuscular relaxants, which are often responsible for postoperative respiratory failure. ${ }^{1-6}$ The arterial blood gas analysis performed immediately after surgery revealed no deterioration in ventilation.

In general, the incidence of respiratory depression after epidural morphine is reported to be low. ${ }^{7-9}$ A nationwide retrospective study of epidural and intrathecal opioids in Sweden by Gustafsson et al. indicated that only 22 of approximately 6,000 patients receiving epidural morphine in doses of 2 to $20 \mathrm{mg}$ developed ventilatory depression requiring reversal by naloxone. ${ }^{8}$ Reiz et al. reported that the incidence of respiratory depression caused by epidural morphine was $0.1 \%$ or less. ${ }^{9}$ Moreover, profound respiratory depression, as in our patient, where the $\mathrm{PaCO}_{2}$ 
value reaches $90 \mathrm{mmHg}$, is seldom observed. This supports the view that the respiratory centre in our patient possessed an abnormal susceptibility to morphine. The extraordinary sensitivity to such a small dose of epidural morphine, to our best knowledge, has never been reported.

It should also be noted that arterial blood gas analysis before the operation revealed an elevation of $\mathrm{PaCO}_{2}$ with a value of $51 \mathrm{mmHg}$ despite nearly normal pulmonary function tests. Such an elevation of $\mathrm{PaCO}_{2}$ is not uncommon in patients with myotonic dystrophy. A previous report demonstrated that the average values of $\mathrm{PaCO}_{2}$ in nine patients with myotonic dystrophy was $\mathbf{5 0}$ $\mathrm{mmHg},{ }^{10}$ indicating that impaired sensitivity of the respiratory centre to carbon dioxide may also be involved. Indeed, a depressed carbon dioxide response curve has been demonstrated in myotonic dystrophy. ${ }^{10,11}$ An elevation of resting $\mathrm{PaCO}_{2}$ seen in this patient was not due to reduced ventilatory volume secondary to respiratory muscle weakness but impaired sensitivity of respiratory centre to carbon dioxide.

Despite many case reports of the systemic administration of opioids in myotonic dystrophy, there are few regarding epidural opioids. ${ }^{5,12}$ Paterson et al. ${ }^{5}$ reported a 29-yr-old woman with myotonic dystrophy who showed no respiratory depression after epidural administration of fentanyl $50 \mu \mathrm{g}$ via an epidural catheter inserted at the $\mathrm{L}_{4-5}$ interspace during Caesarean section. Youssef et al ${ }^{12}$ described a 61-yr-old man undergoing iliofemoral and femorofemoral bypass grafting who had no respiratory complications following continuous epidural infusion of fentanyl at a rate of $50 \mu \mathrm{g} \cdot \mathrm{hr}^{-1}$ via an epidural catheter inserted at the $T_{7-8}$ interspace. The discrepancy between these cases and ours can be explained by the lipidsolubility of the two opioids. Morphine is known to be very poorly lipid-soluble in comparison with fentanyl. ${ }^{7}$ Epidurally administered morphine penetrates the meninges and enters the cerebrospinal fluid (CSF). Thereafter, it spreads slowly cephalad to the respiratory centre in the brainstem. In contrast, fentanyl, a highly lipidsoluble drug, enters the spinal cord rapidly from the CSF and little remains in the CSF. ${ }^{13}$ Serious respiratory depression after epidural administration of fentanyl should occur less frequently than after morphine.

It is important to provide adequate postoperative analgesia in order to prevent postoperative respiratory complications in patients undergoing upper abdominal surgery, especially in patients with myotonic dystrophy in whom the ability to expel sputum is compromised because of muscle weakness. It is generally agreed that epidural morphine has advantages over the systemic administration of morphine, since it has a lower risk of producing respiratory and circulatory depression. How- ever, it should be borne in mind that patients with myotonic dystrophy are highly susceptible not only to the systemic administration of morphine but also to epidural morphine.

In summary, we described severe respiratory depression manifested by a marked elevation of $\mathrm{PaCO}_{2}$ and the absence of a substantial reduction of respiratory rate following epidural morphine $2 \mathrm{mg}$ in a patient with myotonic dystrophy. Only a small dose of epidural morphine can cause unexpected profound respiratory depression in patients with myotonic dystrophy because of the extraordinary sensitivity of the respiratory centre to morphine.

\section{References}

1 Aldridge LM. Anaesthetic problems in myotonic dystrophy: a case report and review of the Aberdeen experience comprising 48 general anaesthetics in a further 16 patients. Br J Anaesth 1985; 57: 1119-30.

2 Katz J, Steward DJ. Anesthesia and Uncommon Pediatric Diseases. Philadelphia: W.B. Saunders Co., 1987.

3 Katz J, Benumof JL, Kadis LB. Anesthesia and Uncommon Diseases. 3rd ed. Philadelphia: W.B. Saunders Co., 1990.

4 Mudge BJ, Taylor PB, Vanderspek AFL. Perioperative hazards in myotonic dystrophy. Anaesthesia 1980; 35 : 492-5.

5 Paterson RA, Tousignant M, Skene DS. Caesarean section for twins in a patient with myotonic dystrophy. Can Anaesth Soc J 1985; 32: 418-21.

6 Hannon VM, Cunningham AJ, Hutchinson M, McNicholas $W$. Aspiration pneumonia and coma - an unusual presentation of dystrophica myotonia. Can Anaesth Soc J 1986; 33: 803-6.

7 Cousins MJ, Mather LE. Intrathecal and epidural administration of opioids. Anesthesiology 1984; 61: 276-310.

8 Gustafsson LL, Schildt B, Jacobsen $K$. Adverse effects of extradural and intrathecal opiates: report of a nationwide survey in Sweden. Br J Anaesth 1982; 54: 479-86.

9 Reiz S, Westeberg $M$. Side-ffect of epidural morphine (Letter). Lancet 1980; 2: 203-4.

10 Kilburn KH, Eagan JT, Sieker HO, Heyman A. Cardiopulmonary insufficiency in myotonic and progressive muscular dystrophy. N Engl J Med 1959; 261: 1089-96.

11 Carroll JE, Zwillich CW, Weil JV. Ventilatory response in myotonic dystrophy. Neurology 1977; 27: 1125-8.

12 Youssef $M S$. Extradural fentanyl and dystrophia myotonica (Letter). Anaesthesia 1989; 44: 360-1.

13 Bromage PR, Camporesi EM, Durant PAC, Nielsen CH. Rostral spread of epidural morphine. Anesthesiology 1982; 56: 431-6. 